\title{
Reaching millennials: a brief proposal for promoting university programs to young millennials
}

\section{Corina Sîrb•}

\begin{abstract}
:
Millennials are "digital natives. They were born in a connected, perpetually communicating environment and thus they are accustomed to finding all the information they need by a simple web query. This feature, corroborated with the increasing competition between universities in their attempt to attract students, stresses the need to find an answer to the following questions: how should academic representatives reach millennials, in order to promote their educational offers? What communication strategy should they follow? What tone of voice and media channels should they use? In order to find an answer to any of the above questions, I think the first step is to analyze the public and their decision-making process. And that is what I will try to do in the first part of the present paper, based on which I later make a clear proposal of a communications strategy
\end{abstract} Key words: millennials, digital communication, social media, university programs

\section{Introduction}

Promoting goods and services to younger publics is quite challenging, as both marketers and researchers in the field of communication note. In his book, Marketing to Millennials, Jeff Fromm makes the case that all those who were born in the late 90s represent a specific kind of public - at least from a marketing point of view - and therefore should be addressed accordingly.

According to many social studies that have been made in the recent years (see, for example, The 2016 Millennial Impact Report conducted by Achieve, Millennials. Political Explorers, conducted by Third Way or the many studies on this matter developed by Pew Research Centre), millennials are all those who were born in the late 80s and beginning of

\footnotetext{
- West University of Timisoara, corina.sirb@e-uvt.ro 
the 90s. Their main characteristic is that they were born in a profoundly digitalized world, and that is why they know intuitively how to use every new gadget that appears on the market. Moreover, their sociological and cultural environment is different from the ones of the previous generations: they were raised in a free and more open-minded environment and thus they are used to be granted freedom of speech, freedom of choice and freedom of action. (Tapscott 2008, p. 35)

Millennials are often called "digital natives", a term used for the first time in the Declaration of the Independence of Cyberspace(1996), to define the only generation for which new technologies are not something they had to learn and adapt to, but a natural environment they were born and raised in. Keeping this in mind, it is not a surprise that millennials are the most avid internet users. According to a Third Way report on millennials social behaviour (2017), it seems that nine in ten millennials are online. They are wirelessly connected when away from home or work (62\%). Three-quarters of Millennials use social networking sites (e.g., Facebook or Twitter). And 55\% of Millennials check those sites daily (or multiple times per day).

The conclusion of the same studies mentioned above stress the fact that millennials were born in a connected, perpetually communicating environment and thus they are accustomed to finding all the information they need by a simple web query. Moreover, they were raised in the spirit of questioning authorities, which makes their relationship with public institutions, universities included, rather conflictual. This idea is also developed by Dan Tapscott (2008).

Taking into consideration all these specific features of this generation, I think that it is important to give our attention to a less popular, but rather urgent communication challenge: how should academic representatives reach young millennials, in order to promote their educational offers? What communication strategy should they follow? What tone of voice and media channels should they use? How informal and "user friendly" can an academic communications representative be in order to achieve his goals? These are the main questions I am trying to answer in the present paper. 


\section{Who are young millennials and what do they want?}

As stated in the introduction, millennials' generation includes all those people who were born beginning with the late 80s until the first years of the 21st century and their main defining features come from the fact that they were born and raised in the middle of the digital revolution, acquiring impressive adaptive skills, flexibility and mobility:

"Not willing to be passive consumers any longer, this generation wants to actively participate, co-create, and, most important, be included as partners in the brands they love. Often, the co-creation process begins with the product or service design, includes the customer journey or shopping experience, and is more easily seen in the marketing and social media space closer to the end of the marketing cycle." (Fromm \& Garton, 2013, p. 8) This definition brings to discussion another specific characteristic of young millennials: they are prosumers. The word prosumer is a hybrid between consumer and producer, which means that they are no longer satisfied with being just at the "receiving” end of the marketing processes. They want to get involved and, even more, they want to be taken into consideration in the communication and production processes. The term is not a new one, it began to circulate in the '80s and it referred to the professional consumer, focusing especially on users of high-performance audio-video equipment. At about the same time, Alvin Toffler (1980), talks about the prosumer as a new type of consumer, which produces much of the goods he consumes.But the digital environment is the one which brought new nuances to this notion. A prosumer is not only confined to consuming products and services, he will also share his experience on his social accounts and he will try to influence their production process.

The prosumer is a kind of unsolicited advocate of companies, who will articulate his opinions publicly and with frankness whenever he will feel the need. Prosumers strive to be part of the production process. They know theyare well informed and feel responsible to improve the products and services they consume. This idea is in tone with the conclusions of the social studies mentioned earlier in this article. For example,according to the researchconducted both by Achieve (2016) and Georgetown University (2012),millennials have a different relation with social institutions. Their unlimited access to information, together with the diversity of media resources and the worldwide 
connectivity, contributed to increased expectations regarding public institutions' activity and transparency.

Closely related to this idea, Dan Tapscott (2008) gathers a list of principles and values that define the generation formed by young millennials, that I think that are very relevant to the way they perceive both educational institutions and media channels. Firstly, they expect to have liberty of action, ranging from liberty of choice to liberty of expression. This characteristic is significant especially during the process of university scouting and seeking information about various educational programs. Not only do they want do be in charge of this decision, but they also expect to find the same feeling of liberty and openness in the institutional communication strategy.

Secondly, they are used to customizing their products, experiences and interactions. As stated previously, they are prosumers, a quality that affects not only their relations with goods and products, but also with services, more specifically, it affects the interactions they have with educational programs. In my opinion, on the one hand, it influences their expectations regarding the communication with the institution's representative, as prosumers expect to find dialogue partners at the other end of the line, not just information transmitters. On the other hand, the content strategy that an institution follows should englobe different forms of user generated content, so that prosumers feel actively involved in the institutional activity.

Thirdly, Tapscott adds, they are used to investigate institutions, brands and service providers. They have a big appetite for information seeking and expect organizations to put resourceful channels at their disposal. Another thing one must consider is that young millennials need speed, especially as far as information exchanges are concerned.Next, millennials are looking for common grounds (from an axiological point of view) with the institutions they collaborate with. This implies that an educational institution should find a way to share its organizational values, in amore or less explicit manner. It may be a declaration of principles, a personal manifesto or just a more personal tone of voice.

In addition, Tapscott depicts young millennials as playful beings, who expect to have fun even at school and work. In my opinion, this is less a matter of age and more a matter of the generation they belong to. As stated before, millennials are more relaxed, detached and in consequence approach all aspects of their life with humour, which should be taken into 
consideration when creating a communication strategy that is directed at them as a core target. This idea is also confirmed by a research conducted by Quacquarelli Symonds (2017), which analysed both the way millennials gather information about educational programs and how universities use digital media and reached the conclusion that higher education establishments that want to appeal to their audiences on social media should cleverly balance academic-related content with creative posts their fans will want to engage with. That is the reason why itis important to mix educational and branded content with light-hearted pieces of information.

Last, but not least, millennials are the generation of cooperation and communication. Their decisions are influenced by the people they are networking with. This observation brings to attention not only the importance of constant communication, but also the need to nurture alumni relations and business to business contacts.

\section{Promoting educational services to young millennials: media channels}

Besides millennials' personality, the way they use media in searching is also important. In order to have a clearer picture of how they use certain channels and why, here is some relevant data extracted from two complex social studies: Millennials and Education (2017), conducted by Echelon Insights and How do Millennials research universities (2017), conducted by Quacquarelli Symonds:

- Official websites of educational establishments are perceived as an essential source of information. $71 \%$ perceive them as the most essential tool for online research, while $90 \%$ of respondents rated official websites as at least 'quite important' to their searches.

- Social media is regarded by respondents as important predominantly for creating an image about their university choices. This sustains my idea that I will develop later on in this article, that websites are used for getting information, while social accounts reveal the organizational culture and personality.

- Information about finances and applications is usually the hardest to find online, even though it is of great importance. 
- Students are increasingly researching universities on mobile devices. This is relevant because information is read differently on mobile, and content creators should use styles and formats that are mobile friendly.

- Email remains the most popular communication tool in this context. $80 \%$ of respondents said their ideal method of being contacted by universities was email, and $67 \%$ felt the same way about initiating a communication with universities themselves.

As a personal conclusion of the abovementioned facts and figures, it appears that, from a communications point of view, a university representative should make sure that the institution they promote respects the following principles:

1. It is reachable

Information about educational programs and admissions should be found easily by a simple descriptive query.

2. It is informative

All important information should be found on the main information channels that the institution owns and/or manages.

3. It is open to dialogue

The willing to engage in dialogues with prospective students should transpire in the organizational tone of voice, but this is not enough, as far as communication tactics are concerned. Thus, the educational institution should implement specific technical features to enable successful dialogue, be it a chat room, a forum or a communication representative that is always available to answer the phone, emails or online messages.

4. It is user friendly

Being user friendly refers mainly to two aspects regarding communications. Firstly, the tone of voice, meaning the used vocabulary, the imagery, the manner of addressing the public etc. Secondly, it refers to user experience, user interface and information architecture. The communication channels, whether we are talking about the classical web page or a mobile app, should offer useful information in a natural, pleasant and effortless 
manner. The way information is structured, categorized, filtered and presented makes a significant impact on the way it is perceived, not to mention that it can even determine the user to abandon the information query.

\section{A Young Millennial Client Persona}

Before heading to sketching a communications strategy model, I would like to use a valuable marketing instrument and create a persona that represents the target audience. A persona is a fictional, but accurate character that represents the main categories of the public that is being targeted. In other words, I gathered the most representative data we have on young millennials and imagined a character that reunites their strongest and most specific features. In this way, finding the way to reach and communicate to them is easier. This persona should offer the answers to the following questions:What are their needs and aspirations regarding the process of choosing an educational program? How do they search for information and where?

Below is how I think such a persona should look like: 


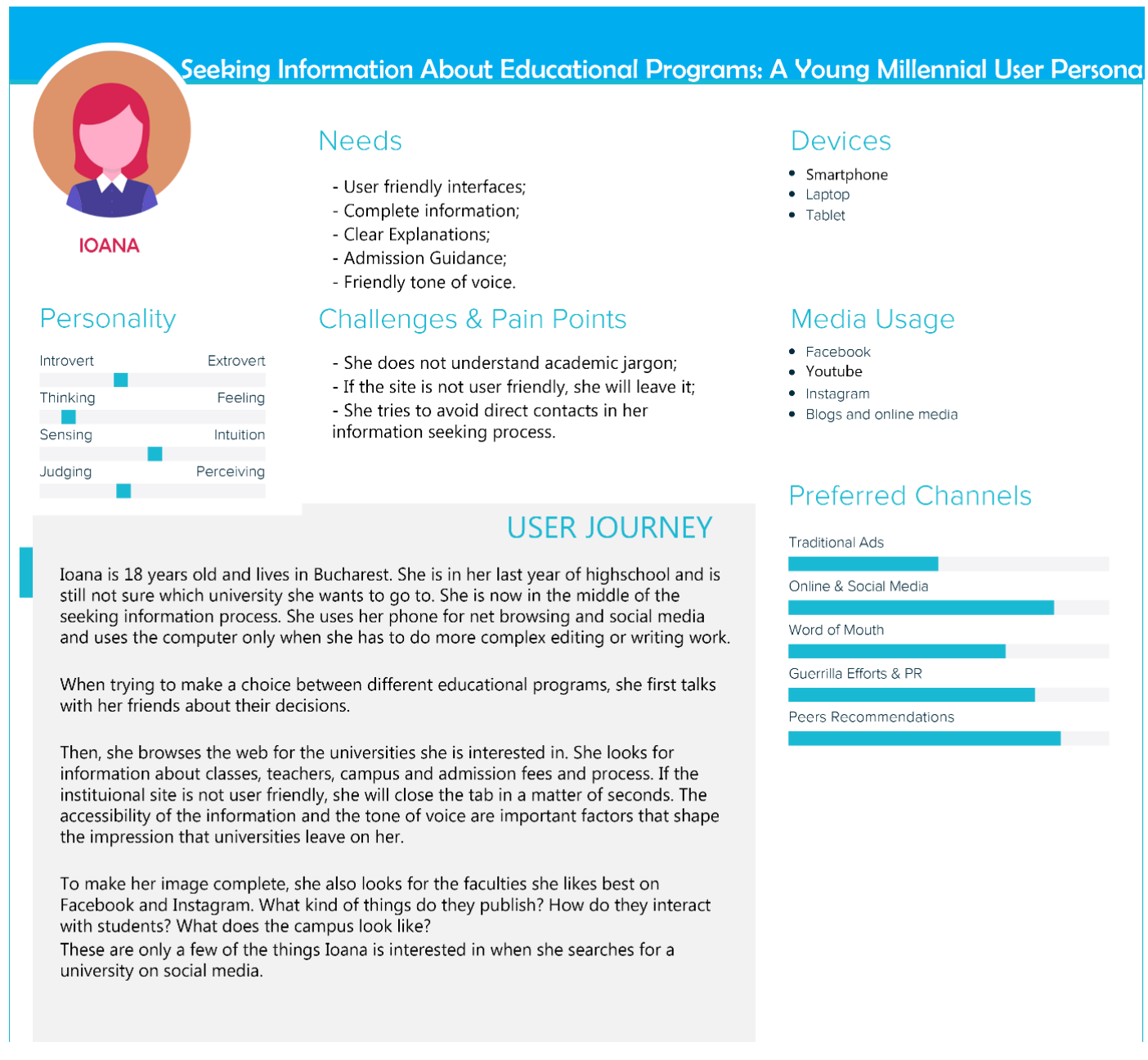

\section{Proposing a structure for admissions web pages}

As seen earlier in the present paper, websites are the main source of information when trying to conduct a research on prospective universities. Unfortunately, most university/faculty webpages are not up to date, both from a user experience perspective and an informational one.

In my opinion, the best way to channel and measure the activity during research and admissions is to create a dedicated page, where the information is written and organized for this specific target. Take into consideration the fact that when a highschool student enters a university website, he probably feels lost in all that academic jargon and rapidly abandons his journey. 
A dedicated page for admissions is not only better for search engine optimization, but it is also more efficient to organize the information this way. There is no pre-existent structure and the audience feels they are given more attention.

As far as the content published on the site is concerned, I think a WHY- WHERE HOW triad suits all kinds of university programs and satisfies young millennials already discussed profile. I will explain it below

So, first, there should be some type of message about the institutional image and reputation, its mission and values. Then, an identification of common grounds with the prospective students. What is the profile of the typical student, what are his dreams and expectations and where does the institution steps in in making them possible. Thus, the audience is given a sense of community, trust and a feeling of belonging.

The WHERE is the place where educational programs are presented. It is the section where the educational establishment should offer answers to the following questions: what is your educational offer? what kind of job and qualifications is it preparing me for? who will be my teachers?

The HOW is where prospective students are guided through the admission process, step by step. Downloadable documents should be at their disposal, whenever it's possible. It is very important that they are easily reachable from a mobile device. If at least a part of the admission process can be achieved online, it is recommended to do so. Rules, regulations, taxes and calendar should be clearly presented and explained in a userfriendly form.

\section{Proposing a direction for social media content}

Besides creating an appealing and informative website, it is important to build a strong presence on social media, so that the audience could get a sense of the organization's brand culture and personality. As far as content is concerned, I propose another triad, this time focused on the topics that are brought to discussion on the institutional social accounts: ACTIVITY - PEOPLE - COMMUNITY Institutional activity 
The topics should concern the day to day activity of the educational institutions: events, special courses, administrative decisions, student guidance, news and advice etc. The People

This approach gives the institution a human side, as it brings forward the people behind the programs, both teachers and students. It is all about creating an organizational personality and friendly tone of voice.

The Community

By building up an organizational community, young millennials, which, as we have seen, are prosumers, are given the time and place to get involved and shape institutional decisions and actions.

\section{Old-school tactics and new technology}

Besides digital communication, direct meetings are essential. But the common educational fairs are no longer enough. They too play an important role in reaching the communication objectives, but to my mind, they do not have enough persuasive powerfor the public we have described. Personal branded events are a good solution to fill this gap, whether it is an annual big conference or smaller events, specifically targeted to special audiences, like summer schools or courses, scholarship contests, special guest conferences, informal meetings with prospective students, CSR or charity work.

If direct contacts are hard to acquire, technology can be used to simulate them. More exactly, there are hi-tech solutions that can help prospective students get a vivid impression about the institution's community and personality. Below are a few of the solutions that I think are best fitted in this context:

- virtual reality videos,

- augmented reality applications,

- live sharing events,

- 360 degree videos,

- branded mobile games and apps,

- $\quad$ interactive microsites. 


\section{Conclusions}

In my opinion, taking into consideration the profile of their target audience, educational institutions must follow the path of commercial organizations and think efficient promotional strategies to convince prospective students to apply. To succeed in this complicated mission, their communication representatives must keep in mind the fact that they are addressing an audience with slightly different habits regarding their needs, expectations and, more importantly, regarding the way they use media; the persona I sketched hopefully succeeds to illustrate this idea.

Taking all this into consideration, to my mind, a great importance should be given to the admissions webpage, for which the why-where-how triad is an appropriate content strategy. Besides this, other communication tactics should not be forgotten: social media posts for conveying the organizational personality; personalized, branded events for direct contact with the audience; and new technology for simulating direct contacts when face to face meetings are not possible.

\section{References:}

Achieve. (2016).The 2016 Millennial Impact Report. Retrieved from:

https://www.givingtuesday.org/lab/2017/03/2016-millennial-impact-report-final-report

Echelon Insights. (2017). Millennials and education. Walter Family Foundation. Retrieved from:http://echeloninsights.com/wp-content/uploads/2017/09/ech-2-report.pdf

Fromm, J, Garton, C. (2013). Marketing to Millennials: Reach the Largest and Most Influential Generation of ConsumersEver. New York: Amacom

Georgetown University's Berkley Center for Public Religion Research Institute and

Religion, Peace, and World Affairs. (2012).The Millennial Values Survey. Retrieved from:https://berkleycenter.georgetown.edu/publications/millennial-values-surveyreport

Hopkins, A., Philippou, G.,\&Vannozzi, M.,(2016),How do Millennials research universities. Retrieved from: http://echeloninsights.com/wp-content/uploads/2017/09/ech-2report.pdf

QuacquarelliSymonds .(2017). How do millennials researchuniversities. Retrieved from: http://www.qs.com/portfolio-items/millenials-research-university/ 
Tapscott, D. (2008)Grown Up Digital: How the net Generation is changing the world 